(c) American Dairy Science Association, 2004.

\title{
Comparison of Analytical Methods and the Influence of Milk Components on Milk Urea Nitrogen Recovery
}

\author{
A. B. Peterson, K. R. French, E. Russek-Cohen, and R. A. Kohn \\ Department of Animal and Avian Sciences \\ University of Maryland, College Park 20742
}

\begin{abstract}
The objectives of this study were to compare analytical instruments used in independent laboratories to measure milk urea nitrogen (MUN) and determine whether any components in milk affect the recovery of MUN. Milk samples were collected from 100 Holstein cows fed one ration in a commercial dairy herd with a rolling herd average of $9500 \mathrm{~kg}$. Half of each sample was spiked with $4 \mathrm{mg} / \mathrm{dL}$ of urea $\mathrm{N}$, while the other half was not, to determine recovery. Both milk samples (spiked and not spiked) were sent to 14 independent laboratories involved in the MUN Quality Control Program through National Dairy Herd Improvement Association and analyzed for MUN, fat, protein, lactose, somatic cell count (SCC), and total solids. The laboratories analyzed MUN using CL-10 ( $=3)$, Skalar ( $\mathrm{n}=$ $2)$, Bentley ( $\mathrm{n}=3)$, Foss $4000(\mathrm{n}=3)$ or Foss 6000 $(\mathrm{n}=3)$ systems. When recovery of MUN was evaluated among the 5 analytical methods, the mean recoveries for the Bentley, Foss 6000, and Skalar systems were $92.1(\mathrm{SE}=2.76 \%), 95.4(\mathrm{SE}=10.1 \%)$, and $95.1 \%(\mathrm{SE}=$ $7.61 \%)$, respectively, and did not differ from each other. However, MUN recovery was $85.0 \%(\mathrm{SE}=2.8 \%)$ for the CL-10 system and $47.1 \%$ ( $\mathrm{SE}=9.9 \%$ ) for the Foss 4000 system, both of which differed from the other 3 systems. Recoveries from Foss 4000, Foss 6000, and Skalar varied among laboratories using the same instrument. As initial MUN concentration increased, recovery decreased using the Bentley and CL-10 systems. Increasing milk fat resulted in a decrease in recovery using the Foss 6000 system. For 4 of the 5 methods, recovery of MUN was not associated with specific milk components. Recovery of MUN was inconsistent for laboratories using the Foss 4000 and the Foss 6000 method and using these systems may result in an overestimation or underestimation of MUN.
\end{abstract}

(Key words: milk urea nitrogen, milk component analysis)

Abbreviation key: IRS = infrared spectroscopy.

Received July 22, 2003.

Accepted October 26, 2003.

Corresponding author: R. A. Kohn; e-mail: rkohn@wam.umd.edu.

\section{INTRODUCTION}

Milk urea nitrogen can be a practical indicator of the protein utilization of lactating cows in dairy cattle nutrition programs (Jonker et al., 1999). Monitoring MUN offers the potential to evaluate the protein concentration in lactating cow rations, reduce farm expenses, and reduce environmental nitrogen loading (Jonker et al., 1998). However, this potential depends largely on the accuracy of MUN values from the laboratory.

Each month, National DHIA sends 12 bulk tank samples in duplicate, selected for a range in milk components, to each DHIA laboratory and to reference testing laboratories to characterize accuracy among laboratories (National DHIA, 2003). This procedure may improve accuracy among laboratories, but does not reveal sources of variation and error in MUN measurement. Also, the use of bulk-tank milk may underestimate variation associated with changes in milk composition because of the tighter range in milk components as compared to individual cow milk.

Most laboratories that test for MUN use one of 5 automated methods: CL-10 (Eurochem, 00040 Ardea, Rome, Italy), Skalar (Skalar, Norcross, GA), Bentley Chemspec (Bentley Instruments Inc., Chaska, MN), Foss 4000 (Foss Inc., Eden Prairie, MN), or Foss 6000 (Foss Inc.). The CL-10, Skalar, and Bentley systems calculate MUN by measuring the ammonia formed from urea after treating the sample with urease. The CL-10 measures the change in $\mathrm{pH}$ caused by the release of ammonia. The Skalar and Bentley use a modified Berthelot reaction for colorimetric determination of the ammonia formed from urease hydrolysis of urea. The Foss 4000 system and the newer Foss 6000 system measure MUN indirectly using infrared spectroscopy (IRS).

The first objective of this study was to compare the accuracy of analytical instruments used to determine MUN and identify differences in initial MUN and recovery of added urea. The second objective was to determine whether milk fat, protein, lactose, or SCC influence the recovery of added urea. 


\section{MATERIALS AND METHODS}

\section{Sample Preparation}

In November of 2002, a commercial Holstein dairy herd in Maryland was sampled. Cows averaged 164 DIM and average milk production was $30 \mathrm{~kg} / \mathrm{d}$. Individual milk samples $(1.5 \mathrm{~L})$ were collected from $100 \mathrm{Hol}-$ stein cows and were immediately placed on ice and processed within $4 \mathrm{~h}$ of collection.

Milk from each cow was mixed and then divided into two 750-mL subsamples using volumetric flasks. Each subsample was then transferred to an Erlenmeyer flask. To one flask, $1 \mathrm{~mL}$ of water was added as a control. The other flask was spiked with $1 \mathrm{~mL}$ of urea solution to result in a final concentration of $4 \mathrm{mg} / \mathrm{dL}$ higher than the control. Each flask was inverted 10 times to mix and then divided into 14 randomly numbered $50-\mathrm{mL}$ milk vials containing a preservative (Broad Spectrum Microtabs II, D\&F Control Systems Inc., Son Ramon, CA).

\section{Sample Analysis}

Fourteen independent laboratories were selected based on their participation in the National DHIA MUN Quality Control Program. All milk samples were sent overnight in Refrigerated Styro-Shippers (Lincoln Suppliers Inc., Owatonna, MN). Each set of samples was analyzed on a CL-10 (3 laboratories), Bentley (3 laboratories), Skalar (2 laboratories), Foss 4000 (3 laboratories), or Foss 6000 (3 laboratories). Milk samples sent to each laboratory included 100 spiked and 100 control samples.

\section{Recovery Calculation}

Recovery of added urea $\mathrm{N}$ was calculated by the difference in the analyzed MUN concentration between the control and treated milk samples. This difference was then divided by $4 \mathrm{mg} / \mathrm{dL}$ (amount of urea added) resulting in the fraction recovered, where 1 indicates perfect recovery.

\section{Statistics}

Statistical analyses were performed using PROC MIXED of SAS Version 8 (1999). Contrast statements were used to compare methods and laboratories within methods. The model used to analyze differences in initial MUN concentrations and MUN recovery among laboratories and methods included the random effects of cow and laboratory nested within method and the fixed effect of method as follows:

$$
\mathrm{Y}_{\mathrm{ijk}}=\mu+\mathrm{C}_{\mathrm{i}}+\mathrm{m}_{\mathrm{j}}+\mathrm{L}(\mathrm{m})_{\mathrm{jk}}+\mathrm{e}_{\mathrm{ijk}}
$$

where

$$
\begin{aligned}
\mathrm{Y}_{\mathrm{ijk}} & =\text { observations for dependent variables; } \\
\mu & =\text { overall mean; } \\
\mathrm{C}_{\mathrm{i}}= & \text { random effect of cow } \mathrm{i} ; \\
\mathrm{m}_{\mathrm{j}}= & \text { fixed effect of method } \mathrm{j} ; \\
\mathrm{L}(\mathrm{m})_{\mathrm{jk}}= & \text { random effect of laboratory } \mathrm{k} \text { nested } \\
& \text { within method } \mathrm{j} ; \\
\mathrm{e}_{\mathrm{ijk}}= & \text { residual error. }
\end{aligned}
$$

The nested effects of $\mathrm{L}(\mathrm{m})_{\mathrm{jk}}$ were allowed to have variances that differed among methods. The hypothesis of heterogeneous variances was tested using a likelihood ratio statistic (Littell et al., 1996). Multiple regression models were used to evaluate the effects of milk components on MUN recovery for each analytical method. A full model including the fixed effect of laboratory, milk fat, milk protein, initial MUN concentration, $\log$ SCC, and interactions of each component within laboratory was evaluated. Insignificant $(P>0.10)$ variables and interactions were removed one at a time, and the reduced model resulted for each analytical method. Results are presented as least square means. Significance was noted at $P<0.05$ and trends at $0.05<P<0.10$.

\section{RESULTS AND DISCUSSION}

\section{Recovery Among Methods}

Initial MUN concentration across all methods and laboratories averaged $11.7 \mathrm{mg} / \mathrm{dL}(\mathrm{SE}=1.6 \mathrm{mg} / \mathrm{dL})$ and did not differ among methods $(P>0.10)$. Even though the average initial MUN concentrations were comparable, there were significant differences in the variance of initial MUN among laboratories within the same method (likelihood ratio statistic $\chi^{2}=132.0, \mathrm{df}=4 ; P$ $<0.001$ ). The lowest variation occurred within the CL10 method, while the highest variation occurred within the Foss 4000 method. Additionally, milk fat averaged $4.1 \%(\mathrm{SE}=0.50 \%)$ and milk protein averaged $3.2 \%$ $(\mathrm{SE}=0.34 \%)$.

Recoveries of added urea $\mathrm{N}$ for each analytical method are reported in Table 1. Recoveries for the Bent-

Table 1. Percent recovery of urea nitrogen among analytical methods.

\begin{tabular}{llc}
\hline Method & Recovery $(\%)^{1}$ & SE (\%) \\
\hline Bentley & $92.1^{\mathrm{a}}$ & 2.76 \\
CL-10 & $85.0^{\mathrm{b}}$ & 2.76 \\
Foss 4000 & $47.1^{\mathrm{c}}$ & 9.88 \\
Foss 6000 & $95.4^{\mathrm{a}}$ & 10.1 \\
Skalar & $95.1^{\mathrm{a}}$ & 7.61 \\
\hline
\end{tabular}

a,b,c Means within a column with unlike superscripts differ $(P<$ $0.05)$.

${ }^{1}$ Recovery $=($ Treated MUN - Control MUN $) / 4 \mathrm{mg} / \mathrm{dL}$. 
Table 2. Percent recovery of milk urea nitrogen among laboratories.

\begin{tabular}{lcll}
\hline Laboratory & Recovery $(\%)^{1}$ & SE $(\%)$ & $P$ value $^{2}$ \\
\hline Bentley A & 97.6 & 1.41 & $\mathrm{NS}^{4}$ \\
Bentley B & 88.9 & 1.48 & \\
Bentley C & 89.9 & 1.57 & \\
CL-10 A & 86.7 & 1.33 & $\mathrm{NS}$ \\
CL-10 B & 88.7 & 1.44 & \\
CL-10 C & 79.6 & 1.07 & \\
Foss 4000 A & 46.7 & 5.90 & $<0.0001$ \\
Foss 4000 B & 30.4 & 1.50 & \\
Foss 4000 C & 64.2 & 1.58 & \\
Foss 6000 A & 105.3 & 3.87 & $<0.0001$ \\
Foss 6000 B & 105.8 & 2.39 & \\
Foss 6000 C & 75.3 & 1.39 & \\
Skalar A & 88.3 & 0.84 & 0.0022 \\
Skalar B & 101.8 & 7.72 & \\
\hline
\end{tabular}

\footnotetext{
${ }^{1}$ Recovery $=($ Treated MUN - Control MUN $) / 4 \mathrm{mg} / \mathrm{dL}$.

${ }^{2} P$-value $=$ Significance of difference among laboratories within each method.

${ }^{3} \mathrm{~A}, \mathrm{~B}, \mathrm{C}=$ Denotes different laboratories within a method.

${ }^{4} \mathrm{NS}=$ Not significant.
}

ley, Foss 6000, and Skalar methods were 92.1, 95.4, and $95.1 \%$, respectively, and did not differ from each other $(P>0.10)$. The recovery for the Foss 6000 method may be misleading, however, because 2 laboratories had average recoveries greater than $105 \%$, and the SE for that method was $10.1 \%$. Recovery for the CL-10 method averaged $85.0 \%(\mathrm{SE}=2.76 \%)$ and was significantly lower than the Bentley, Foss 6000, and Skalar methods $(P<0.05)$. However, recovery for the CL-10 method was higher than that of the Foss 4000 method, which averaged $47.1 \%(\mathrm{SE}=9.88 \% ; P<0.05)$. Recovery for the Foss 4000 method, which is an IRS instrument was significantly lower than for all the other methods $(P<0.05)$.

After interviewing several laboratory managers, it was found that the majority of laboratories on this study were using a set of 12 randomly selected bulk tank samples to calibrate the machines on a weekly basis. These samples are first analyzed on a CL-10 instrument as a reference point and are sent out to laboratories to be used for calibration. The range in MUN values varies from week to week and may result in a range as small as 12 to $22 \mathrm{mg} / \mathrm{dL}$ with most samples in the middle of the range. Such a set of calibration samples would place little weight on high or low MUN samples, possibly explaining the inaccuracy of high and low measurements.

There were significant differences in the variance of MUN recovery among laboratories within the same method (likelihood ratio statistic $\chi^{2}=115.6, \mathrm{df}=4 ; P$ $<0.001$ ). The highest variation in recovery occurred within the Foss 4000 and 6000 methods, while the remaining 3 methods had similar low variability.
Table 3. Effect of milk components on milk urea nitrogen recovery.

\begin{tabular}{lll}
\hline Method & Variable $^{1}$ & $P$-value \\
\hline Bentley & Lab & $<0.05$ \\
& Initial MUN (slope $=-1.8 \%$ per mg/dL) & $<0.001$ \\
& Laboratory * lactose & $<0.05$ \\
CL-10 & Laboratory & $<0.0001$ \\
& Initial MUN (slope $=-1.6 \%$ per mg/dL) & $<0.001$ \\
Foss 4000 & Laboratory & $<0.0001$ \\
Foss 6000 & Fat (slope $=-5.8 \%$ per \% fat) & $<0.05$ \\
& Laboratory * fat & $<0.01$ \\
& Laboratory * protein & $<0.01$ \\
Skalar & Laboratory & $=0.10$ \\
\hline
\end{tabular}

${ }^{1}$ Significant variables left in the reduced model.

\section{Recovery Among Laboratories}

To determine whether the recovery for the Foss 4000 and the other methods was consistent across laboratories, each laboratory within a method was evaluated, and results are presented in Table 2 . Since the identity of individual laboratories could not be revealed, each laboratory within a method was identified by a letter (e.g., A, B, or C). There was little variation among recoveries for the Bentley and CL-10 analytical methods, and there were no differences among laboratories within these 2 methods $(P>0.05)$. However, overall recovery using the Bentley method was higher than recovery for the CL-10 method $(P<0.05)$. Therefore the Bentley method is both more repeatable and may be the most reliable way to analyze MUN. Since only 2 laboratories using the Skalar method were evaluated in this study, no assumptions about the repeatability and accuracy of MUN analysis will be made. Two laboratories utilizing the Foss 6000 method had recoveries of over $105 \%$, while the third laboratory had a recovery of only $75.3 \%(P<0.0001)$. As a result, while an average recovery of $95.4 \%$ may appear to be adequate, this method may not be repeatable and may result in an overestimation or underestimation of MUN depending on the laboratory used. Finally, the Foss 4000 method had recoveries ranging from 30.4 to $64.2 \%$, and the recoveries for all 3 laboratories were different from each other $(P<0.0001)$. As a result, not only is the recovery far below what is desirable, resulting in an underestimation of MUN, but there is also too much variation between laboratories to result in an accurate MUN value.

\section{Effect of Milk Components on Recovery}

Because MUN recovery was incomplete and variable among methods and laboratories, milk components were analyzed to determine whether they interfered with MUN recovery. Samples were analyzed for fat, protein, lactose, SCC, and initial MUN. A full multiple 
regression model including laboratory, milk fat, milk protein, initial MUN concentration, log SCC, total solids, and interactions of each component with laboratory was evaluated for each method individually. Insignificant $(P>0.10)$ variables and interactions were removed one at a time, resulting in a reduced model for each analytical method (i.e., a backward variable selection procedure; Kleinbaum et al., 1998). Results from each reduced model are presented in Table 3. Initial MUN concentration had an inverse negative effect on recovery for the Bentley and CL-10 methods, whereby as initial MUN increased, recovery decreased. This effect may be due to the narrow range of standards used by each laboratory to calibrate the instrument. Though significant, the effect on recovery was small at $1.8 \%$ or $1.6 \%$ of recovery per $1 \mathrm{mg} / \mathrm{dL}$ of MUN for the Bentley and CL-10 methods, respectively $(P<0.001)$. It has been previously shown that milk fat percentage is positively correlated with MUN in high-producing herds (RajalaSchultz and Saville, 2003), and that high milk fat may result in misleading MUN values (Carlsson and Bergström, 1994). Milk fat decreased MUN recovery among laboratories using the Foss 6000 method $(P<0.05)$. In this case, there was a decrease in recovery of 5.8 percentage units for every 1 unit increase in fat percentage. Effects associated with laboratory and interactions with laboratory, especially with the Foss 6000 method, may be due to variation in analyzing these components between laboratories.

\section{CONCLUSIONS}

Milk urea nitrogen recovery for the Foss 4000 method was significantly lower than the recovery for the other methods including CL-10, Skalar, Bentley, and Foss 6000 . Additionally, recovery for laboratories using this method was quite variable, ranging from 30.4 to $64.2 \%$. Therefore, analyzing MUN using the Foss 4000 may result in an underestimation for the higher values of
MUN. Since recoveries were greater or less than $100 \%$ for the Foss 6000 method depending on the laboratory, using this system may result in an overestimation or underestimation of MUN. The Bentley instrument was the most repeatable among laboratories and resulted in higher recoveries as compared with the CL-10. This study suggests that improved calibration among laboratories using the same method may improve the reproducibility and accuracy of MUN values. Consistent and accurate MUN values are important if they are to be used to better formulate dairy rations or estimate urinary $\mathrm{N}$ excretion.

\section{ACKNOWLEDGMENTS}

The authors are grateful to Michael Ahalt, owner of Richvale Farms, for assistance and cooperation with this research.

\section{REFERENCES}

Carlsson, J., and J. Bergström. 1994. The diurnal variation of urea in cow's milk and how milk fat content, storage and preservation affects analysis by a flow injection technique. Acta Vet. Scand. 35:67-77.

Jonker, J. S., R. A. Kohn, and R. A. Erdman. 1998. Using milk urea nitrogen to predict nitrogen excretion and utilization efficiency in lactating dairy cows. J. Dairy Sci. 81:2681-2692.

Jonker, J. S., R. A. Kohn, and R. A. Erdman. 1999. Milk urea nitrogen target concentrations for lactating dairy cows fed according to National Research Council recommendations. J. Dairy Sci. 82:1261-1273.

Kleinbaum, D. G., L. L. Kupper, K. E. Muller, and A. Nizam. 1998. Applied Regression Analysis and Other Multivariable Methods. 3rd ed. Brooks/Cole Publishing Co., Pacific Grove, CA.

Littell, R. C., G. A. Milliken, W. W. Stroup, and R. D. Wolfinger. 1996. SAS System for Mixed Models. SAS Inst., Inc., Cary, NC.

National DHIA. 2003. Subject: MUN quality control. http://www. dhia.org/mundata.htm. Accessed Aug. 25, 2003.

Rajala-Schultz, P. J., and W. J. A. Saville. 2003. Sources of variation in milk urea nitrogen in Ohio dairy herds. J. Dairy Sci. 86: $1653-1661$.

SAS User's Guide: Statistics, Version 8 Edition. 1999. SAS Inst., Inc., Cary, NC. 